\title{
ENTRE A RUA E O BAIRRO: ETNOGRAFIA DE UM ESPAÇO EM MOVIMENTO
}

\author{
Natália Helou Fazzioni ${ }^{1}$
}

\section{Introdução: a Lapa em processo}

Ao escolher pesquisar a Lapa, no Rio de Janeiro, faz-se necessário levar em conta o "excesso de visibilidade" 2 que o bairro possui: trata-se de um local intensamente estudado, visitado, narrado e representado. Ou ainda, como atenta Beatriz Kushnir: “(...) A Lapa está sempre em pauta” (2002: 179). Fundamental na consolidação do tecido urbano da cidade, a Lapa existe como bairro desde pelo menos o final do século XVIII, tornando-se especialmente conhecida no início do século XX, quando se povoou de bares e cabarés, tornando-se o epicentro da vida boêmia na cidade do Rio de Janeiro (Casco, 2007, Lustosa, 2001).

Neste trabalho, porém, a Lapa dos cabarés, ou qualquer outra Lapa que tenha ficado no passado interessa apenas a partir do momento em que é rememorada no presente. Proponho pensá-la a partir da ideia de tempos múltiplos e sobrepostos, tornando-se assim possível recorrer à noção de memória em uma análise antropológica que parte do presente para "investigar-se a cidade como objeto temporal a partir da forma como os sujeitos pensam a ordenação de superposições temporais vividas" (Eckert; Rocha, 2005: 89). Ao pensar no espaço por meio das histórias dos sujeitos que se relacionam com ele, estas podem ser interpretadas como elementos que possuem o poder de organizar um todo a partir de um fragmento vivido. Acerco-me, desse modo, das mudanças que ocorreram no bairro a partir das experiências - individuais ou coletivas - de seus agentes no presente.

\footnotetext{
${ }^{1}$ Universidade de São Paulo, Brasil.

${ }^{2}$ Tomo de empréstimo tal expressão, bem como a reflexão suscitada por esta, a partir do que sugerem Graça Cordeiro e Antônio F. da Costa (2006: 61), quando tratam do bairro de Alfama, na cidade de Lisboa, em Portugal (no mesmo artigo o bairro da Bica também é analisado, como contraponto, pelos autores).
} 
Em se tratando de um espaço com ampla visibilidade, torna-se necessário ainda considerar dois planos de análise simultâneos e articulados entre si: as representações que aparecem sobre o bairro publicamente e aquelas decorrentes das práticas ali vividas. Estas não se separam: não há aqui uma primeira imagem do bairro, supostamente "falsa", confrontada a outra nativa, ou "real". Tal distinção torna-se insuficiente na medida em que as representações com maior visibilidade desse espaço são, do mesmo modo, acionadas pelos que estão ali no cotidiano. Por outro lado, as práticas e discursos destes, de igual modo, alimentam e transformam a imagem mais manifesta do bairro. Dar conta dessa situação, portanto, implica trabalhar com a ideia de que ambos os planos de investigação afetam-se mutuamente ${ }^{3}$.

Este trabalho foi desenvolvido entre 2006 e $2012^{4}$ onde procurei compreender, de maneira geral, como se desenvolveu o processo de mudanças na dinâmica da Lapa, desencadeado desde o inicio dos anos 2000, e intitulado na maior parte das vezes de "revitalização". Silvana Rubino (2009) atenta para o fato do termo revitalização e seus análogos (requalificação, reabilitação, etc.) serem problemáticos, pois:

Mais do que meros eufemismos para uma forma contemporânea de limpeza urbana, tais termos passaram a ser 'lugares comuns': palavras guarda-chuva que ao cobrir situações diversas terminam sem significado, ou termos associados a um lugarcomum onde falas diversas se encontram (Rubino, 2009: 34).

Como mostra a autora, o termo evoca a ideia de "limpeza urbana", atualizada em pesquisas recentes pelo debate em torno do conceito de gentrification (ou enobrecimento urbano). A presença da palavra revitalização aqui, portanto, remete diretamente a tal conceito ${ }^{5}$, definido de maneira sintética por Frúgoli Jr., como:

\footnotetext{
${ }^{3}$ Tal perspectiva de análise encontra respaldo em reflexões a respeito de etnografias realizadas em diferentes contextos, tais como: bairros (Cordeiro; Costa, 2006 [1999]), patrimônios culturais (Gonçalves, 2007) e periferias (Feltran, 2010).

${ }^{4}$ Inicialmente tratou-se de uma pesquisa de iniciação científica orientada pela Prof. Dra. Silvana Barbosa Rubino (Unicamp). Em seguida, tornou-se tema de minha pesquisa de mestrado, dando origem à dissertação "A Vista da Rua: etnografia da construção dos espaços e temporalidades na Lapa (RJ)" orientada pelo Prof. Dr. Heitor Frúgoli Jr., defendida em novembro de 2012 na Universidade de São Paulo (PPGAS/USP).

${ }^{5}$ Para um aprofundamento deste debate e trajetória do conceito, ver Rubino $(2004,2005,2009)$.
} 
(...) criação de áreas residenciais para classes médias e altas em bairros de áreas urbanas centrais, articulados a processos de controle ou expulsão de setores das classes populares, num processo também assinalado pelo desempenho de determinados estilos de vida e de consumo, produzindo mudanças da composição social de um determinado lugar bem como tipos peculiares de segregação socioespacial e de controle da diversidade (Frúgoli Jr., 2006a: 133-134 Apud Frúgoli Jr.; Sklair, 2009: 120).

O mesmo autor, no entanto, aponta para o fato de que outros estudos têm demonstrado que tanto em cidades europeias como latino-americanas, tais processos culminaram em uma transformação mais pautada pela ocupação das elites para lazer e consumo e não tanto residencial, como pensada pelos primeiros teóricos a tratarem do tema. O trabalho de Rogério Proença Leite (2004) aponta para o mesmo sentido no processo que ocorreu no Bairro do Recife, em Pernambuco. Nesse sentido, importa aqui entender as especificidades do caso da Lapa nesse contexto sem necessariamente o atrelar ao conceito de gentrification, o qual ainda que crucial, parece possuir pouca capacidade explicativa sobre o que de fato se deu em cada um dos contextos onde esses processos ocorreram. Como afirma Michel Agier (2008: 21), apreender a cidade significa atentar para os processos que a fazem existir, e foi o que busquei fazer neste trabalho ao não partir de uma conceituação mais generalista sobre este fenômeno. Procurei, portanto, compreender a Lapa vivida, sentida e em processo. 


\section{Desvelando a "revitalização" e a "diversidade"}

No caso da Lapa, uma análise inicial do processo consistiu em refletir sobre a sua dinâmica através de materiais escritos sobre ou com referência ao bairro; tais como folders publicitários com anúncios de lançamentos imobiliários e eventos; matérias de jornais e revistas; trabalhos acadêmicos que analisavam as políticas públicas destinadas à Lapa nos últimos trinta anos, a importância do samba e da música no processo de revitalização da Lapa, entre outros ${ }^{6}$.

Um dos dados provenientes da análise deste material apontou para a problematização de um discurso que afirmava a ideia de que a Lapa era um bairro que, por excelência, congregava a diversidade cultural e social da cidade. Um destes discursos é de Plínio Fróes, empresário ligado ao Polo Novo Rio Antigo e proprietário da casa Rio Scenarium, entre outras, que declarou em reportagem à Folha de S. Paulo, o seguinte: “A Lapa é o nosso Pelourinho, mas com muito mais diversidade cultural. Aqui convivem em harmonia, estudantes, travestis, empresários, prostitutas" (Vianna, 06/01/2008). Na Revista Serafina, pertencente ao mesmo jornal citado acima, um artigo sobre o bairro informa que a Lapa é "um corpo vivo, que contém todos os tempos e ritmos do Rio" (Seixas, 01/10/2010). E ainda, Perfeito Fortuna - criador da casa de show Fundição Progresso e também um dos fundadores do Circo Voador - aponta no mesmo sentido quando diz:

A Lapa é uma Torre de Babel ao contrário. Apesar das diferenças, todo mundo se entende. Quem vem aqui é o inteligente de cada classe: o rico que sabe das coisas e gosta de boa música, o pobre que faz a cabeça do pessoal em Belford Roxo [Baixada Fluminense]... A inteligência está aqui.

Estes discursos fazem referência a algo facilmente constatado em uma caminhada pelo bairro em qualquer noite de sexta-feira: há uma pluralidade de indivíduos e grupos - proveniente de diferentes pontos da cidade - que frequenta o espaço do bairro, sobretudo aos finais de semana, para atividades de lazer e

\footnotetext{
${ }^{6}$ No primeiro capítulo de minha dissertação de mestrado, realizo uma análise mais atenta e minuciosa desse processo ( $c f$. Fazzioni, 2012).
} 
sociabilidade, envolvendo, sobretudo, o consumo de bebidas alcoólicas e a frequentação de bares e casas de show ${ }^{7}$.

No entanto, este discurso também possui outros desdobramentos. Nas eleições para a prefeitura da cidade em 2008, a Lapa tornou-se um importante ponto de debate entre os candidatos que disputavam o cargo. Em reportagem que apresentava quais eram as propostas de cada um para reduzir a "desordem urbana" na Lapa (O Globo online, 18/07/2008), o próprio Perfeito Fortuna foi entrevistado e declarou: "Como é uma região vasta em que não mora muita gente, ninguém cuida e qualquer um ocupa. $\mathrm{E}$ como não tem muito voto, parece que as reivindicações não valem muito".

A declaração de Fortuna chamava atenção negativamente para o fato de que o local pode ser ocupado por qualquer um, algo que comumente aparece como um de seus grandes atrativos. Tal ambiguidade, contudo, diz muito sobre o processo ocorrido na Lapa nos últimos, onde a atuação governamental é vista pela maioria como discreta ou pouco efetiva, enquanto a os próprios frequentadores e os investidores privados teriam ditado os rumos das transformações recentes no bairro, a despeito das políticas públicas implementadas no local (Jacques; Vaz, 2003, Herschmann, 2007).

Fato é que somente na década de 1990 e início dos anos 2000 surgiram políticas públicas mais elaboradas destinadas ao bairro, para além das ações de tombamento e reformas de vias; referindo-se não apenas à preservação do patrimônio edificado, mas igualmente à sua utilização. Estas ações, no entanto, na maior parte dos casos, não ocasionou um processo de mudança no entorno dos imóveis quando foram utilizados, por exemplo, para a instalação de equipamentos culturais - como no caso dos equipamentos que se instalaram no inicio da Avenida Mem de Sá em 1992. Os grupos Centro de Teatro do Oprimido, Tá na Rua, Casa de Cultura Hombu e FEBARJ (Federação de Blocos Afro e Afoxés do Rio de Janeiro) receberam a cessão de uso dos imóveis no inicio dos anos 1990, no entanto, só presenciaram a transformação de seu entorno a partir dos anos 2000, quando os cariocas já frequentavam massivamente as

\footnotetext{
${ }^{7}$ Para ilustrar, vale lembrar que enquanto o circuito de samba e choro é constantemente anunciado e celebrado pela mídia como o símbolo da Lapa, outros gêneros musicais também encontram na Lapa forte centralidade, como é o caso do rap. Em documentário intitulado "L.A.P.A." (Borges; Domingos, 2007) são mostrados os encontros em festas e rodas de breaks organizados na Lapa pelos músicos ligados a este circuito e residentes em diferentes partes da cidade. Ainda em meu trabalho, demonstrei a centralidade do bairro na consolidação de um circuito de jovens que acompanharam um grupo de jazz em sua formação a partir de jam sessions em um botequim na Lapa (Fazzioni, 2012).
} 
ruas de praticamente toda a Lapa nas noites de sexta-feira e sábado.

Ao contrário, nos locais onde houve a abertura de novos bares e casas de shows - sobretudo ligados ao circuito do samba ${ }^{8}$ - a mudança foi impactante, não apenas fisicamente, mas também afetando toda a dinâmica do entorno, em razão do aumento de frequentadores pouco habituais à Lapa anteriormente. O principal exemplo deste caso hoje está no final da Rua do Lavradio, onde se encontra o "Quarteirão Cultural da Rua do Lavradio", trecho fechado por catraca para passagem de carro através de decreto municipal em 2007. Ali estão os bares mais elitizados da Lapa, como o Rio Scenarium e o restaurante Mangue Seco, além de antiquários e outras lojas.

Dados de pesquisa realizada pelo Data UFF em 2004 mostraram que a Lapa possuía já naquele ano: “(...) 116 estabelecimentos do setor musical, teatral, gastronômico, antiquário, turístico e comercial de modo geral. Ao todo 110 mil pessoas frequentando o bairro por semana, gerando uma economia de aproximadamente 14,5 milhões de reais por mês" (Herschmann, 2007: 26). A presença dos estabelecimentos é sentida, evidentemente, todos os dias. No entanto, o fluxo de pessoas em torno destes é claramente maior nas noites de sexta-feira e sábado. Dados de 2007, repassados pelo 13 Batalhão da Polícia Militar (Caruso, 2010: 82), apontavam que o bairro atraía nesse período, em média, trinta mil pessoas a cada sexta-feira.

A partir dos anos 2000, ocorreram intervenções policiais que buscaram coibir, sobretudo, o tráfico de drogas e a existência de ambulantes na região. A primeira denominou-se "Operação Lapa Limpa", conduzida pela Polícia Militar, que teve seu inicio em 2003 (Folha Online, 25/04/2003, Caruso, 2009). Em 2009, após a eleição de Eduardo Paes (PMDB) para a Prefeitura Municipal, a presença do termo "revitalização" da Lapa em seus discursos passou a ser também recorrente. Em seus primeiros seis meses de governo, o prefeito lançou o programa "Lapa Legal", que dispunha de uma série de medidas de planejamento destinadas ao bairro (O Globo on-line, 24/06/09) e que propunha realizar a "revitalização" da Lapa, a partir de propostas como a criação de

\footnotetext{
${ }^{8} \mathrm{O}$ trabalho de Herschmann (2007) foi pioneiro em analisar a importância do circuito do samba, frequentadores, músicos e empresários, na consolidação desse processo na Lapa. Góes (2007) procura de maneira similar a Herschmann (2007) explicitar o circuito ligado ao choro na Lapa. Requião (2010) demonstra, em uma análise iluminada pelo marxismo, a exploração da mais-valia através dos músicos trabalhadores da Lapa, prejudicados pela falta de legalização no ramo - o estudo de caso empreendido pela pesquisadora focaliza as relações de trabalho no bar Rio Scenarium. Frydberg (2010) analisa a descoberta da cidade através da experiência de jovens músicos na Lapa e em Alfama (Lisboa).
} 
uma feira noturna para organizar os ambulantes e o fechamento das ruas para passagem de carros nas noites do final de semana (a primeira proposta foi concretizada e perdura até hoje; a segunda durou somente dois anos). Já em 2014, em seu segundo mandato, Paes lançou o programa "Lapa Presente" cujo objetivo anunciado foi conter a violência ocasionada pelo processo de revitalização, marcada por assaltos e assassinatos nas imediações do bairro.

A partir deste material, foi possível notar que o discurso de que a Lapa aglutina grupos e indivíduos heterogêneos entre si, desdobra-se também na ideia de que o bairro foi, está sendo, ou será "revitalizado" constantemente, anunciada em diferentes versões. Tal ideia aparece sendo atribuída ou "auto atribuída" a músicos, frequentadores, empresários e por vezes, até ao poder público. Deste modo, saber quem "revitalizou" a Lapa, quando e como isso aconteceu é uma indagação que se abre para muitas respostas.

Em uma alusão às diferentes mitologias que cercam o bairro, seria o equivalente a tentar descobrir se Geraldo Pereira de fato morreu nas ruas do bairro do soco que lhe deu Madame Satã nos anos 1950. ${ }^{9}$ Sobre esta e outras narrativas que giram em torno da Lapa, Millôr Fernandes, frequentador assíduo e que chegou também a viver no bairro, escreveu:

Pois é, foi ali (ou não foi ali), no Capela (ou não foi no Capela?), que Madame Satã (ou não foi Madame Satã?) matou (ou não matou?), com um soco só! (ou uma facada?), o grande GTP, o sambista Geraldo Pereira ("O escurinho era um escuro direitinho/ Agora está com mania de brigão")? Tudo é lenda! (Fernandes, 2007 [1965]: 10).

Tal paralelo serve para ilustrar que também no caso da "revitalização", não existe uma narrativa mais verdadeira que a outra, mas sim uma disputa em relação à "autoria" do processo que parece na realidade se caracterizar justamente por diferentes ações que ocorreram em momentos distintos. No entanto, além dos jornais e discursos oficiais sobre o bairro, esta mesma dinâmica se estabelece nas ruas do bairro onde diferentes versões sobre o processo de transformação do bairro emergem e a noção de uma Lapa diversa e democrática ganha contornos mais precisos.

\footnotetext{
${ }^{9}$ Trata-se de uma narrativa popular e com diferentes versões que conta que após ter sido chamado de "viado" pelo sambista Geraldo Pereira, Madame Satã teria lhe dado um soco. O sambista, após esse fato, foi encontrado hospitalizado e dias depois, morreu.
} 


\section{Dois lados, uma rua}

Caminhar pela Lapa em uma sexta-feira à noite consiste em encarar um cenário completamente modificado daquele existente durante os outros dias da semana. Um exercício inicial de observação da dinâmica do local permitiu realizar um mapeamento dos lugares, principais práticas e tipos de frequência existentes. Um dado bastante revelador decorrente dessa análise foi a ideia de uma divisão espacial no bairro balizada pelos Arcos da Lapa $^{10}$ - a saber: "antes e depois dos Arcos" - sendo comum o entendimento de que predominam em cada um dos lados de tal monumento, situado no coração da Lapa, formas distintas de ocupação do espaço noturno, que se diferenciam pela relação de contraste entre ambas, mas que internamente, congregam um conjunto heterogêneo de práticas e lugares.

Nesse sentido, diferenças relativas à classe social possuem um papel importante no entendimento desta divisão ${ }^{11}$, trata-se, a princípio, de um lado mais empobrecido e outro mais elitizado, tanto do ponto de vista dos frequentadores, quanto dos moradores, o que pode ser igualmente constatado pelo tipo das edificações existentes em cada um dos lados.

A Rua Joaquim Silva está no lado considerado mais empobrecido, isto é, "antes dos Arcos". É conhecida pela presença majoritária de uma população de classe popular, pelos diversos casos de assaltos, assim como pela atuação do tráfico de drogas na região, constantemente anunciada na mídia ${ }^{12}$. A rua situa-se em uma região da Lapa onde predominam edifícios de conjugados voltados às classes populares e também habitações coletivas, neste contexto chamadas de "cabeça de porco". ${ }^{13}$ Cabe salientar

\footnotetext{
${ }^{10}$ Sobre a centralidade que certos monumentos exercem em relação ao bairro onde se localizam ou ao entorno de forma geral, Walter Benjamin, em "Passagens", ao refletir sobre os monumentos parisienses, escreve: "Servindo de fundo a ruas importantes, eles concedem aos quartiers um centro de gravidade e, ao mesmo tempo, representam neles a cidade enquanto tal." (Benjamin, 2007 [1982]: 567).

${ }^{11}$ Claudia Fonseca (2005: 133-134) atenta para o fato de que assim como gênero, etnia, entre outros, a noção de classe, livre de suas possíveis reificações, constitui também um recorte interpretativo bom para pensar, desde que inserido em uma etnografia que revele experiências cotidianas e assim, conflito, movimento e ambivalência em sua análise.

${ }^{12}$ Alguns exemplos de reportagens que tratam de acontecimentos que se deram na Rua Joaquim Silva são: "Polícia estoura 'boca de fumo' em bar na Lapa". O Dia online: 05/09/09; "Assalto e morte no Centro". O Dia online: 11/02/2009; "Operação da polícia prende 13 acusados de tráfico na Lapa (RJ)". Folha Online: 25/04/2003; isso dentre outras matérias.

${ }^{13} \mathrm{O}$ cortiço é um dos muitos tipos de habitação coletiva que, se distinguem das moradias individuais, unifamiliares. A presença de habitações deste tipo na região central do Rio de Janeiro remonta ao final do século XIX e início do XX, quando a cidade experimentou um espantoso crescimento demográfico.
} 
que em toda a Lapa, mas especialmente neste lado, existem vários edifícios e sobrados funcionando como cortiços. Prevalecem ali bares, restaurantes e distribuidoras de bebidas populares.

A rua congrega um fluxo significativo de turistas estrangeiros em razão da presença da Escadaria Selarón ${ }^{14}$, que a conecta ao bairro de Santa Teresa e que foi decorada com azulejos coloridos pelo falecido artista plástico chileno de mesmo nome, tornando-se assim um importante ponto turístico da cidade. À noite, entretanto, sobretudo na sexta-feira, a escadaria se transforma, tornando-se um ponto de frequentação jovem, assim como boa parte da Rua Joaquim Silva. Apesar de não possuir uma feira noturna organizada pela prefeitura ou ter sido fechada para passagens de carro pela mesma, a dinâmica que ali se estabelece funciona basicamente a partir dessa mesma lógica. Além dos bares, várias barracas e carrinhos se espalham entre as calçadas dos dois lados da rua - que são estreitas -, tornando a circulação de carros bastante dificultada. Existem ainda os vendedores que circulam pelo local com produtos na mão e se misturam em meio às pessoas que ocupam a rua.

Os produtos oferecidos são muitos e variados: bebidas em geral, churrasquinho, caipirinha, yakissoba, mini-pizza, batata frita, artesanatos, camisetas. Há ainda todo um trecho dedicado a produtos ligados à cultura rastafári. Por mais ou menos dez metros a passagem na rua é feita por uma área onde se escuta principalmente reggae, vendem-se camisetas com temas dedicados ao cantor Bob Marley, cachimbos feitos de durepox e outros artefatos similares. E, por fim, o odor do local não deixa dúvidas sobre o intenso consumo de maconha que ali é feito.

Durante o trabalho de campo, o nome que mais ouvi para se referir a este tipo de moradia foi "cabeça de porco". Tal termo se tornou popular na cidade devido à existência de um grande cortiço de mesmo nome, marco na história urbana do Rio de Janeiro, em razão da operação de despejo de seus moradores em 1893 (Chalhoub, 1996: 15-19).

${ }^{14}$ A Escadaria Selarón (também conhecida como Escadaria da Lapa), que liga o bairro da Lapa ao de Santa Teresa, tem 215 degraus, todos revestidos com mosaicos de azulejos e cerâmicas coloridas. Em 1990, o artista plástico chileno Jorge Selarón, radicado no Rio de Janeiro desde 1983, resolveu iniciar a restauração da escadaria que leva ao Convento de Santa Teresa. Passou assim a decorá-la em seus 215 metros de extensão com vários azulejos provenientes de mais de 60 países. Em 2005, a Escadaria Selarón foi tombada pela Prefeitura do Rio de Janeiro e, no mesmo ano, Jorge Selarón morreu assinado na própria escadaria em 2013. Ver o trabalho de Raquel Carriconde (2012) para uma analise antropológica da dinâmica da escadaria e a figura de Selarón. 
Depois desse trecho, a movimentação na rua diminui e volta a se intensificar na esquina com a Travessa do Mosqueira, onde existe um bar com música ao vivo e novamente na altura da Escadaria Selarón. A Polícia Militar fica sempre posicionada em frente a esta, com um ou dois carros. A partir do trecho onde começa a Escadaria, a movimentação de pessoas é quase nula e depois volta a se intensificar mais abaixo, próximo à Rua da Lapa, onde existem outros bares mais movimentados, como o popular Beco do Rato.

A Rua Joaquim Silva chamou-me a atenção desde o início por representar uma espécie de radicalização do que seria este lado dos Arcos. Passei então a centralizar meus esforços em entender melhor a dinâmica local, compartilhando da ideia já proposta por outros antropólogos (tais como Santos \& Vogel, 1985: 24) de que a rua pode ser pensada como "um recorte etnográfico possível para a exploração e o conhecimento da vida urbana contemporânea a partir de baixo e de dentro" (Cordeiro; Vidal, 2008: 9).

Mais do que um microterritório, a Rua Joaquim Silva poderia servir como ponto de partida e ao mesmo tempo como limite da etnografia. A análise não se restringiu às relações existentes nessa rua e seu entorno, no entanto, partiu-se destas para compreender o bairro e as relações que o pressupunham como referência. Assim, importa aqui compreender as diferentes determinações que a Lapa recebe e também emana, a Rua Joaquim Silva torna-se um ponto privilegiado de observação, mas igualmente um ponto de vista da Lapa. Um lugar de onde se contempla o bairro, mas que, ao mesmo tempo, permite refletir sobre o próprio ponto de contemplação.

\section{Domingo: o samba de Aline e as "brincadeiras" de Marlene}

O domingo na Rua Joaquim Silva é o dia menos intenso nos finais de semana com relação à movimentação de frequentadores. No período em que a etnografia foi realizada, um bar específico se beneficiava justamente desta calmaria presente no bairro para dar lugar as suas principais atrações musicais, o bar Semente. Situado na Rua Joaquim Silva, esquina com a Rua Evaristo da Veiga, o Semente existe desde 1997 e tem como dia mais importante e movimentado em seu calendário de shows, justamente o domingo. Uma das razões é aproveitar a pouca movimentação de pessoas e camelôs 
na rua, já que as principais atrações do bar são shows de música ao vivo e instrumental, constituindo uma exceção no contexto de bares daquela rua, a maior parte botequins sem música ao vivo. O barulho que vem de fora, portanto, muitas vezes atrapalha os músicos e a apreciação do público do Semente, segundo sua proprietária. A trajetória do local se articula à ideia de que a Lapa "renasceu" através da música e principalmente do samba. É nesse contexto que o bar se encontra, sendo considerado "um dos pioneiros" no processo de "revitalização" do bairro.

Aline, atual proprietária, é gaúcha e veio viver no Rio de Janeiro em 1997, para fazer um curso de mestrado em Engenharia de Produção. Em sua narrativa sobre como se estabeleceu a relação com o bar, ela conta que sempre gostou de música, especialmente choro e samba, e acabou se aproximando do circuito existente na Lapa como frequentadora, até se tornar produtora e abandonar sua área de trabalho para se dedicar exclusivamente ao bar. Segundo Aline, nesse mesmo ano, 1997, o Semente começou a existir como bar quando um casal de amigos, Regina Weissmam e Oswaldo Krowoski, frequentadores do restaurante de comida natural que já possuía o nome de Semente, resolveram alugar o imóvel e transformá-lo em bar quando souberam do fechamento deste ${ }^{15}$. Com o tempo, o Semente acabou se transformando em um importante palco para músicos de samba e de choro e Regina passou a ser considerada, de acordo com Aline, "uma espécie de mecenas da música”, por abrir espaço a músicos iniciantes na casa. Em 2001, já frequentadora assídua do bar, a gaúcha ajudava Regina com a programação. No ano seguinte, no entanto, os proprietários não quiseram dar continuidade ao bar e fecharam as portas. Estavam endividados com os custos do estabelecimento e o imóvel precisava de reformas.

Passado um tempo, contudo, um grupo de frequentadores descobriu que Regina ainda seguia pagando o aluguel do imóvel, apesar de manter o bar fechado e resolveram propor um projeto que consistia em uma forma de reabrir o bar somente aos domingos entre amigos, em que cada um faria um pequeno investimento inicial de dinheiro e todos trabalhariam nas noites nas diferentes funções. Os músicos tocariam de graça e haveria ainda cobrança de uma taxa de entrada que seria investida na reforma da casa. Nessa época, o bar se chamou "Comuna do Semente", devido ao caráter coletivo do empreendimento.

\footnotetext{
${ }^{15}$ Tais informações também constam na já citada matéria de jornal sobre o bairro (Pimentel, 13/04/2008).
} 
Após o fim da Comuna, Aline menciona que Regina não pôde mais pagar o aluguel e ela acabou assumindo o Semente sozinha. Abandonou a proposta da Comuna e a partir daí, diz: "me apeguei à única coisa que eu poderia me apegar: a música e os músicos”. No período da entrevista, 2011, tinha também como sócio o músico Yamandú Costa. Às sextas-feiras, o Semente não abre, não só devido ao fato de que Aline está envolvida em outro evento, mas também pelo excesso de barulho na rua existente hoje na rua, que praticamente inviabiliza a apresentação dos músicos dentro da casa. Ainda sobre o bar, ela diz que aos poucos o vem "profissionalizando" e o tornando "sustentável". O maior desafio, diz Aline, é estar em um "lado da Lapa tardio na chegada da revitalização". Ela completa:

A história da legalização do Semente é difícil aqui na Lapa, os casarões são antigos, tombados e tem uma coisa de ser um lugar de entretenimento, cultural, diversão e também tem uma questão das pessoas morarem aqui que não combina, não é funcional (...) Eu estou numa área que está muito degradada ainda, a valorização não chegou aqui.

Aline identifica que a existência de moradores nessa região seja um impeditivo para a prosperidade de seu negócio. No entanto, dirige suas críticas também ao poder público quando diz que a única melhoria que viu nos últimos anos foi a pintura dos Arcos da Lapa ${ }^{16}$. Mas apesar da pintura, ela diz, moradores de rua seguem dormindo embaixo do monumento e os vendedores ambulantes seguem trabalhando nas ruas da Lapa, atividade a qual ela se opõe fortemente. Estas questões geram um problema que Aline identifica não apenas como uma questão visual, mas como algo que afasta um público potencial de seu bar. O Semente, no entanto, é um dos bares associado ao Polo Novo Rio Antigo, associação na qual Aline diz que insiste em discutir a "questão da Rua Joaquim Silva”. Para ela, contudo, entre os donos de bares associados ao Polo, há uma disputa com relação à obtenção de benefícios. Neste caso, como os proprietários de estabelecimentos na Rua Joaquim Silva associados ao Polo são minoria, estes teriam menos poder, em oposição a outros, como, por exemplo, os da Rua do Lavradio.

\footnotetext{
${ }^{16}$ Os Arcos da Lapa foram restaurados em 2011, tendo o processo consistido basicamente na limpeza e pintura dos mesmos. Para o evento Copa do Mundo de 2014, a pintura foi refeita.
} 
Apesar disso, Aline diz sobre o entorno: "Eu sou apaixonada por esse lado, acho que é o mais lindo e o mais mal aproveitado, além de ser uma beleza internacional". Na reforma que pretende para o Bar Semente, pretende fechar as janelas, para que o barulho do público da rua do lado de fora não atrapalhe mais do lado de dentro. No entanto, isto será feito com janelas de vidro acústicas para não perder a tão valorizada vista dos Arcos da Lapa, mencionada inclusive, como a própria Aline lembra, pela cantora Marisa Monte em reportagem sobre o bar quando comenta: "Já estive lá diversas vezes, em noites memoráveis (...) Gosto muito da atmosfera, do público da Lapa e da janela dando para os Arcos" (Pimentel, 13/04/2008).

Aline ressalta ainda o fato de que, apesar de todos os problemas, acredita possuir um público fiel e que se diferencia de outras casas da Lapa, como o Carioca da Gema e o Rio Scenarium, por ser menos turística e valorizar mais a música de qualidade. Ela diz que apesar de muitas vezes essas outras casas levarem os créditos por terem supostamente lançado músicos como Teresa Cristina e o Casuarina, todos eles começaram, na verdade, no Semente. Assim ela reforça ainda mais a importância da música, sobretudo do samba, em seu vínculo afetivo e profissional com o bairro, bem como seu papel de pioneira nesse processo.

Assim como Aline, que se beneficia da tranquilidade dos domingos para oferecer atrações musicais de qualidade em seu bar, o mesmo ocorre com os moradores da Rua Joaquim Silva. Se a sexta-feira é um dia de lazer para as pessoas que vêm de fora para a Lapa e para a rua, para os moradores, o dia principal de lazer é outro: o domingo. Luís, proprietário de um extinto botequim na rua, costumava trazer um grupo de pagode de sua cidade natal, Magé, para tocar no domingo, aproveitando para celebrar aniversários de amigos e vizinhos. Considerava este o dia "mais importante" para o bar, apesar de lucrar menos do que na sexta.

Marlene, uma das moradoras mais antigas da rua e liderança comunitária também organiza aos domingos suas "brincadeiras na rua" voltadas especialmente para as crianças (como festa de São João e São Cosme e Damião) ou para os membros de sua família (aniversários, batizados, entre outros). O uso da rua se coloca para os moradores da Rua Joaquim Silva como algo constante e cotidiano. Não é, de maneira alguma, apenas uma via de acesso às suas casas. Ali, muitas vezes trabalham, como fazem os camelôs na noite de sexta-feira. Da mesma forma, colocam cadeiras para conversar na 
rua ou mesmo se sentam no meio fio para conversar e brincar, no caso das crianças. A rua torna-se quase uma extensão da casa ${ }^{17}$.

Os laços de Marlene com a rua são de ordens distintas daqueles de Aline. Ela vivi ali há quase cinquenta anos. Segundo ela, a Lapa sempre foi também seu local de trabalho - agora, pela primeira vez, com carteira assinada em um projeto social que oferece aulas de informática e idiomas para moradores; mas antes como camelô vendendo doces, quentinhas, bebidas e o que mais fosse preciso. É na rua também que vivem seus amigos, seus familiares, as pessoas de quem gosta; sendo difícil separar em sua relação com a Lapa seus papéis de moradora, trabalhadora, liderança, entre outros.

Conheci Marlene em 2008, durante uma visita que fiz para conhecer o projeto social onde trabalhava. Nesse dia, acabei gravando uma entrevista com ela, pois logo notei se tratar de alguém que conhecia muito bem a Lapa ${ }^{18}$. Ao ser perguntada sobre o processo de "revitalização" naquele momento, Marlene respondeu:

Fui eu que comecei isso aqui, sabia? Foi assim, a Lapa não tinha nada, então eu comecei, eu morava ali debaixo dos Arcos, perto do Arco da Velha [bar], então aos sábados como não tinha nada na rua eu inventei de fazer um pagode, aí vinham os meninos de Santa Teresa e faziam. Aí foi crescendo, pessoal daqui mesmo, da área. E aos domingos eu fazia uma peixada, ou uma feijoada e vendia, não caro, ou dava ou vendia, era assim. E fazia o pagode, ficava assim [de cheio] debaixo dos Arcos. E fazia bingo e fui crescendo.

A narrativa de Marlene inicialmente me causou desconfiança por se tratar de um discurso comum de lideranças comunitárias, que atribuem a si muitos feitos, buscando valorizar seu papel nos locais onde vivem. Somente mais tarde, contudo, convivendo intensamente com Marlene quando passei a dar aulas de inglês no projeto onde ela trabalhava e frequentar a rua diariamente, pude compreender a importância deste discurso.

\footnotetext{
${ }^{17} \mathrm{O}$ questionamento da dicotomia entre casa e rua não é novidade na discussão urbana contemporânea. Cabe notar, no entanto, que no Brasil tal dicotomia tornou-se notória através dos estudos de Roberto DaMatta, inspirados na reflexão de Gilberto Freyre (DaMatta (1997 [1984]): 16). Como demonstra Agier (2011: 84), a mesma distinção está presente sistematicamente nos estudos urbanos norte-americanos "tributários de um a priori ecológico durante muito tempo".

${ }^{18}$ Entrevista gravada com Marlene no dia 29 de maio de 2008.
} 
A percepção de que a Lapa antes era escura e mais perigosa não é tampouco exclusiva de Marlene. Muitos que já circulavam pelo bairro ou vivem ali há muitos anos ressaltam a questão da luminosidade e dos assaltos. Dadá, filha de Marlene, menciona que houve momentos distintos na história da Lapa antes da recente efervescência: "Tinha tempo em que a gente nem podia sair de casa, de tão perigoso. Mas tinha época muito boa, quando todo mundo se encontrava para brincar na rua, fazer bloco de carnaval”. Entre aqueles que procuravam dar mais ânimo ao bairro, ela ressalta o papel de sua mãe, dizendo que Marlene sempre gostou de organizar estas festas, mesmo no tempo em que boa parte da população local era composta por travestis. Dadá menciona que Marlene "armava um palco debaixo dos Arcos e botava os viado [sic] para fazerem show". Ao lado, é claro, Marlene aproveitava para vender suas bebidas e "quentinhas" que fazia na época ${ }^{19}$.

Uma das festas que participei na rua foi, como de costume, organizada por Marlene, no dia das crianças. Ela conseguiu apoio de alguns comerciantes locais, sobretudo donos de bares, para comprar presentes para as crianças e instalar um pulapula. Os preparativos foram feitos dentro do projeto social no qual Marlene é secretária e também em sua própria casa, que fica logo em frente. Enquanto ela e outras mulheres preparavam baião de dois e outros quitutes em sua casa, no espaço do projeto, um grupo de pessoas organizava os saquinhos com presentes e doces que seriam dados às crianças.

Acompanhei outras festas ali, tais como o aniversário do neto de Marlene, a festa de São João, o aniversário de sua filha, além do dia das crianças e a festa de encerramento e entrega de certificados aos alunos do projeto social. Tais festas são profundamente familiares e ganham relevância justamente pela peculiaridade de ocorrerem na rua. O “Arraiá da Tia Marlene”, assim como outras datas comemorativas,

\footnotetext{
${ }^{19}$ Ao ler o livro de Hélio Silva (2007) intitulado "Travestis: Entre o espelho e a rua", tomei contato com esta esfera de sua vida: Marlene foi uma das interlocutoras do antropólogo em seu trabalho de campo feito na Lapa na virada dos anos 1980 para os 1990. De maneira primorosa, Silva explora etnograficamente a vida dessas pessoas que viviam ou apenas trabalhavam no bairro na época. A Lapa, contudo, não é um mero cenário na etnografia do autor na medida em que ele está constantemente preocupado em descrever como era o lugar onde suas interlocutoras trabalhavam: "uma área de travestis, mais precisamente, de prostituição de travestis" (op. cit.: 45). O autor ainda indica que o "aspecto viário" da Lapa (op. cit.: 109), com fluxo intenso de passagem de carros, era precondição para a abordagem de clientes aos travestis, isto é, a Lapa era, mais do que tudo, um ponto de passagem de carros e não de permanência durante a noite.
} 
possuem um caráter distinto dos aniversários porque envolvem em geral uma parte maior da população das redondezas. Nas festas de São João, por exemplo, muita gente é mobilizada, pois nesta ocasião as comidas, assim como as bebidas, são vendidas e não dadas e além do espaço da calçada no qual ficam as mesas, utiliza-se também o próprio asfalto, por exemplo, para quando as crianças dançam quadrilha. Apesar de ser a principal agitadora de festas na rua da região, Marlene não faz este tipo de uso do espaço da rua sem a mobilização de outras pessoas.

Quero com isso dizer que encontrei na Rua Joaquim Silva outros "pioneiros" do processo de "revitalização" da Lapa, tais como Marlene que diz ser a primeira dali ou mesmo Aline que reivindica para o Bar Semente um lugar de destaque dentro do circuito de bares ligados ao samba no bairro, nem sempre lembrado como ela gostaria. No caso de "pioneirismo" de Marlene, os personagens não são o samba e a malandragem, mas sim pagodes, shows de travestis e até festas infantis. O período também muda, tudo começou antes dos anos 2000. As festas organizadas ocorrem, e sempre ocorreram, na rua e quem as organiza não são empresários da cultura e sim, camelôs e moradores. Os Arcos da Lapa são também o cenário, mas, nesse caso, ainda mais próximos. O contraste destas narrativas com aquelas recorrentes na mídia não serve, no entanto, para afirmar que essas histórias da "revitalização" da Lapa são distintas daquelas antes contadas. Elas se tornam, ao contrário, mais um elemento que atesta o caráter desse processo: aquele sobre o qual muitos reivindicam certa autoria.

\section{Dos encontros aos conflitos: uma Lapa singular}

A peculiaridade de um olhar mais atento à dinâmica da Rua Joaquim Silva permite colocar lado a lado experiências centradas em espaços distintos: o bar Semente e a rede de relações de sua proprietária, em um primeiro momento, e, em seguida, as festas organizadas por uma moradora da rua e sua rede de amigos e familiares. O domingo é o momento de encontro entre essas experiências. Aline, a dona do Bar Semente tem nesse dia seu maior público e seu estabelecimento é conhecido por atrações musicais de samba e choro. A alguns metros dali, Marlene mobiliza sua família e amigos para fazer um baião de dois, instalar um pula-pula na rua para as crianças e tocar - em um aparelho de som acoplado a um amplificador - o disco de sua cantora preferida: Alcione. Elas não se conhecem, tampouco se encontram ali nesses domingos. 
O modo como habitam a Lapa é completamente distinto e isso, por um lado, as afasta. No entanto, de alguma maneira, a Lapa que habitam é também a mesma e assim se aproximam e fazem, cada uma a seu modo, o mesmo espaço existir.

Isso reforça algo já dito sobre o bairro: trata-se de um lugar de encontros entre atores sociais distintos. Encontros que nem sempre são presenciais, como no caso de Aline e Marlene, que praticamente não se encontram. Ambas, no entanto, se orgulham de ter como cenário de suas "festas" os Arcos da Lapa e aproveitam a calmaria do domingo para desempenharem atividades importantes. Entretanto, Aline entende que "não combina" com a Lapa a presença de moradores como Marlene. E Marlene, há mais de cinquenta anos, vive ali. Novamente elas se encontram, mas dessa vez revelando a oposição de seus mundos.

Entre aqueles que vivem na Lapa e quase não saem do bairro, e os que passarão por lá apenas uma vez em toda a vida, como os turistas que visitam a Escadaria Selarón, nenhum é mais ou menos importante em sua constituição. A diversidade de pessoas, usos e discursos que marcam a existência desse espaço é, em um primeiro momento, apenas um dado óbvio sobre o bairro, fácil de ser constatado em uma rápida caminhada por suas ruas. A partir das experiências descritas aqui, no entanto a mesma diversidade se reafirma de maneira reflexiva. A existência de muitos mundos dentro da própria Lapa é certamente um de seus elementos mais marcantes quando a olhamos à distância. Contudo, ao combinar estes olhares, distantes e aproximados, sua peculiaridade reside justamente no que tange aos encontros, muitas vezes permeados por conflitos e disputas, entre esses mundos. 


\section{Referências}

AGIER, Michel. "O 'Acampamento', a cidade e o começo da política”. In: Cordeiro, G., Vidal, F. (orgs.). A Rua: espaço, tempo, sociabilidade. Lisboa: Livros Horizonte, 2008, p. 17-25.

BENJAMIN, Walter. Passagens. Belo Horizonte: Editora UFMG, São Paulo: Imprensa Oficial do Estado de São Paulo, 2009.

CARUSO, Haydée. Entre ruas, becos e esquinas: por uma antropologia dos processos de construção da ordem na Lapa carioca. Tese de Doutorado. Programa de PósGraduação em Antropologia Social da Universidade Federal Fluminense (UFF), 2009.

- "Choque de ordem na Lapa”: Uma análise sobre as lógicas e práticas de policiamento no 'centro cultural' do Rio de Janeiro. In: Kant de Lima, R., Eilbaum, L., Pires, L. (orgs.). Conflitos, direitos e moralidades em perspectiva comparada. Vol. 1. Rio de Janeiro: Garamond, 2010, p. 71-110.

CASCO, Ana Jara. O Arco das Lapas: Um Estudo de Antropologia Urbana. Tese de Doutorado. Programa de Pós-Graduação em Antropologia Social do Museu Nacional/UFRJ, 2007.

CARRICONDE, Raquel. Nas subidas e descidas da Escadaria Selarón, Lapa/RJ: uma etnografia da construção social do espaço. Dissertação de mestrado. PPCIS/UERJ, 2012.

CHALHOUB, Sidney. Cidade Febril: cortiços e epidemias na corte imperial. São Paulo: Companhia das Letras, 1996.

CORDEIRO, Graça Índias. Um lugar na cidade: Quotidiano, Memória e Representação no Bairro da Bica. Lisboa: Publicações Dom Quixote, 1997.

CORDEIRO, Graça Índias, COSTA, Antônio Firmino da. "Bairros: Contexto e Intersecção". In: Velho, G. (org.). Antropologia Urbana: cultura e sociedade no Brasil e em Portugal. Rio de Janeiro: Zahar, 2006 [1999], p. 58-79.

CORDEIRO, Graça Índias, VIDAL, Frédéric. "Introdução". In: Cordeiro, G., Vidal, F. (orgs.). A Rua: espaço, tempo, sociabilidade. Lisboa: Livros Horizonte, 2008. pp. 9-15.

DA MATTA, Roberto. A casa e a rua: espaço, cidadania, mulher e morte no Brasil. Rio de Janeiro, Rocco: 1997 [1985].

ECKERT, Cornélia, ROCHA, Ana Luísa. O tempo e a cidade. Porto Alegre: UFRGS Editora, 2005.

FAZZIONI, Natália Helou. A Vista da Rua: etnografia da construção dos espaços e temporalidades na Lapa (RJ). Dissertação de mestrado. Programa de Pós-Graduação em Antropologia Social (USP), 2012.

FELTRAN, Gabriel de Santis. "Periferias, direito e diferença: notas de uma etnografia urbana”. Revista de Antropologia Urbana, n. 2, vol. 53, 2010, p. 565-610. 
FERNANDES, Millôr. “A Lapa”. In: Damata, G (org.) Antologia da Lapa: vida boêmia no Rio de ontem. Rio de Janeiro: Desiderata, 2007 [1965]. pp. 9-11.

FONSECA, Claudia. "La Clase Social y su Recusación Etnográfica”. Revista Etnografías Contemporáneas 1, 1, 2005, p. 117-138.

FRYDBERG, Marina. “Alfama não cheira a fado, mas não tem outra canção ou Tudo isso é a alma do Rio, é samba: As cidades descobertas através do samba, do choro e do fado". Revista Ponto Urbe. Vol. 7, Ano 4: Dezembro de 2010. Disponível em: http://www.pontourbe.net/edicao6-artigos/108-alfama-nao-cheira-a-fado-mas-nao-temoutra-cancao-ou-tudo-isso-e-a-alma-do-rio-e-samba-as-cidades-descobertas-atraves-dosamba-do-choro-e-do-fado (Acessado em 08/06/2011).

FRÚGOLI JR., Heitor; SKLAIR, Jessica. “O bairro da Luz em São Paulo: questões antropológicas sobre o fenômeno da gentrification". Cuadernos de Antropologia Social, n.30, 2009, p. 119-136.

GÓES, Cláudia. "O choro na Lapa: comunicação, movimento musical e "revitalização" do Rio Antigo". Revista Os Urbanitas Vol 4, n5, 2007. Disponível em: <http://www.aguaforte.com/osurbanitas5/Goes2007.html > (Acessado em 20/07/09).

GONÇALVES, Reginaldo S. Antropologia dos Objetos: coleções, museus e patrimônios. Rio de Janeiro: Garamond, 2007.

HERSCHMANN, Micael. Lapa, cidade da música: desafios e perspectivas para o crescimento do Rio de Janeiro e da indústria da música independente nacional. Rio de Janeiro: Mauad X, 2007.

JACQUES, Paola B.; VAZ, Lilian F. “A cultura na revitalização urbana. Espetáculo ou participação?”. Espaço e Debates, n. 43-44, 2003, p. 131-140.

KUSHNIR, Beatriz. "A Lapa e os filhos da revolução boêmia". Revista Estudos Históricos, Rio de Janeiro, 30, 2002, p. 174-180.

LEITE, Rogério Proença. Contra-Usos da Cidade: lugares e espaço público na experiência urbana contemporânea. Campinas, SP: Editora da Unicamp; Aracaju, SE: Editora UFS, 2004.

LUSTOSA, Isabel. “À luz difusa do abajur lilás”. In: Lustosa, Isabel (org.). Lapa do desterro e do desvario: uma antologia. Rio de Janeiro: Casa da Palavra, 2001, p. 11-18. REQUIÃO, Luciana. Eis aí a Lapa: processos e relações de trabalho do músico nas casas de show da Lapa. São Paulo: Annablume, 2010.

RUBINO, Silvana. "Gentrification: notas sobre um conceito incômodo". In: Benfatti, D; Schicchi, M (orgs.). Urbanismo: dossiê São Paulo - Rio de Janeiro. Campinas: Puccamp/Prourb, 2004, p. 287-296.

A curious blend? City revitalization, gentrification and commodification in Brazil. In: Atkinson; Bridge (org.). Gentrification in a Global Context. Londres: Routledge - Taylor and Francis Group, 2005. p. 225-239. 
. "Enobrecimento Urbano". In: Fortuna, C., Leite, R. (orgs.).

Plural de Cidade: novos léxicos urbanos. Coimbra: Almedina, 2009, p. 25-40.

SANTOS, Carlos N. F.; VOGEL, Arno. Quando a rua vira casa: a apropriação de espaços de uso coletivo em um centro de bairro. São Paulo: Editora Projeto, 1985.

SILVA, Hélio R. S. Travestis: entre o espelho e a rua. Rio de Janeiro: Rocco, 2007.

SILVEIRA, Carmen; VAZ, Lilian “A Lapa Boêmia na Cidade do Rio de Janeiro: Um

Processo de Regeneração Cultural? Projetos, Intervenções e Dinâmica do Lugar”. In:

Vargas, H.; Castilho, A. L. (orgs.). Intervenções em Centros Urbanos: Objetivos, estratégias e resultados. São Paulo: Manole, 2006. pp. 67-99.

\section{Filmografia}

"L.A.P.A.”. Cavi Borges; Emílio Domingos (diretores). Brasil: Cavídeo, Virtual Filmes, 2008 .

\section{Material de imprensa}

FOLHA ONLINE. “Operação da polícia prende 13 acusados de tráfico na Lapa (RJ)". Folha Online: 25/04/2003. Disponível em:

http://www1.folha.uol.com.br/folha/cotidiano/ult95u73726.shtml (Acessado em 15/03/2010).

GOULART, Gustavo. "Turista francês morre ao cair de bonde na Lapa, e menores roubam objetos da vítima". O Globo Online: 24/06/2011. Disponível em:

http://oglobo.globo.com/rio/turista-frances-morre-ao-cair-de-bonde-na-lapa-menoresroubam-objetos-da-vitima-2758425 (Acessado em 13/06/2012).

O GLOBO. "Eduardo Paes entrega restauração dos Arcos da Lapa". O Globo Online: 26/03/2011. Disponível em:

http://oglobo.globo.com/rio/mat/2011/03/26/eduardo-paes-entrega-restauracao-dosarcos-da-lapa-924096269.asp (Acessado em 08/06/2011).

O GLOBO. "Prefeitura anuncia primeiras medidas do Lapa Legal nesta quarta-feira." O Globo on-line: 24/06/09. Disponível em:

http://oglobo.globo.com/rio/mat/2009/06/24/prefeitura-anuncia-primeiras-medidas-dolapa-legal-nesta-quarta-feira-756486834.asp (Acessado em 15/07/09).

O GLOBO. "Candidatos apresentam suas propostas para reduzir a desordem urbana na Lapa". O Globo on-line: 18/07/2008. Disponível em:

http://oglobo.globo.com/eleicoes-2008/candidatos-apresentam-suas-propostas-parareduzir-desordem-urbana-na-lapa-5001622 (Acessado em 15/07/09). 
O DIA ONLINE. “Assalto e morte no Centro". O Dia online: 11/02/2009. Disponível em:

http://odia.terra.com.br/portal/rio/html/2009/9/assalto_e_morte_no_centro_33431.html (Acessado em 12/02/2010).

PIMENTEL, João. "Samba de Semente". O Globo: 13/04/2008. Segundo Caderno (Página 1).

RODRIGUES, Charles. "Polícia estoura 'boca de fumo`em bar na Lapa". O Dia online: 05/09/09. Disponível em:

http://odia.terra.com.br/portal/rio/html/2009/9/policia_estoura_boca_de_fumo_em_bar_ na_lapa_33431.html (Acessado em 12/02/2010).

SEIXAS, Heloísa. "Mutante Carioca". Revista Serafina (Folha de S. Paulo): outubro de 2010. P. 72.

SILVA, Beatriz Coelho. "A progressão geométrica do samba na Lapa”. O Estado de S. Paulo: 21/01/2007. Caderno 2.

VIANNA, Luiz Fernando. “A reinvenção da Lapa". Folha de São Paulo: 06/01/2008. C8, C9.

Recebido em: 30/09/2014 Aprovado em: 18/11/2014 